\section{Ser mujer y estudiar leyes: aproximaciones antropológicas al acoso y su resistencia en una universidad pública de la Ciudad de México, México}

\author{
Being a woman and studying laws: anthropological \\ approaches to harassment and their resistance \\ at a public university in Mexico City, Mexico
}

Ser mulher e estudar as leis: abordagens antropológicas do assédio e a sua resistência em uma universidade pública da Cidade do México, México

\section{Resumen}

En este artículo se describen algunas prácticas de acoso en educación superior y se explica por qué se naturalizan. También se documentan las formas de resistencia narradas por algunas estudiantes y profesoras. Entre enero de 2016 y marzo de 2017 se hicieron nueve entrevistas en profundidad con estudiantes que experimentaron acoso en una escuela pública que imparte la carrera de leyes en la Ciudad de México, México, además se entrevistaron a tres estudiantes varones y a dos profesoras. Los hallazgos sugieren que algunos profesores acosan selectivamente, con base en códigos de vestir relacionados con los estereotipos de género. El acoso puede ser visto como un castigo ejemplar, pues tiene fines correctivos, es decir, es parte de la disciplina escolar $y$ de la formación identitaria de las estudiantes en esta institución. También se detectaron formas de vigilancia heteronormativa que naturalizan el acoso, al punto en que algunas lo consideran parte de un modo de vida al que hay que adaptarse para poder concluir los estudios. Otras han encontrado maneras de denunciar, a través de estrategias informales, con las que han contribuido a visibilizar y desnaturalizar esta violencia de género. Por ejemplo, algunos docentes establecen el uso de falda como requisito para presentar exámenes, sin embargo, este mandato no siempre es acatado por las estudiantes y quienes se niegan a obedecer han organizado movimientos de resistencia estudiantiles. Hasta ahora no existe una intervención de las autoridades que garantice a las mujeres espacios libres de acoso, esto hace evidente la necesidad de crear estatutos y reglamentos en educación superior que permitan definir estos delitos como graves, para así prevenir el acoso sexual.
Daniel Hernández-Rosete 1 Juan Carlos Gómez-Palacios 1

doi: 10.1590/0102-311X00024620
Correspondencia

D. Hernández-Rosete

Departamento de Investigaciones Educativas, Centro de Investigación y de Estudios Avanzados, Instituto Politécnico Nacional.

Calz. Tenorios 235, Col. Granjas Coapa, Ciudad de México 14330, México.

danielshr204@yahoo.com.mx

1 Centro de Investigación y de Estudios Avanzados, Instituto Politécnico Nacional, Ciudad de México, México. 


\section{Introducción}

En México el acceso a la educación media y superior muestra un aumento notable en la matrícula femenina, en el caso de la Universidad Nacional Autónoma de México (UNAM) se puede observar que en todos sus niveles educativos (bachillerato, licenciatura y posgrado), el número de mujeres $152.514(50,7 \%)$ que se incorporó a las aulas es mayor al de varones 148.332 (49,2\%) (Centro de Investigaciones y Estudios sobre Género, Universidad Nacional Autónoma de México. Población estudiantil. https://tendencias.cieg.unam.mx/brecha_estudiantil.html, accedido el Feb/2020). Sin embargo, algunas investigaciones sugieren que la vida universitaria no está acompañada de cambios en las creencias masculinas sobre el papel social de la mujer, al punto en que el acoso sexual aparece como una forma de mandato social 1 En otro estudio, Corleto et al. 2 observaron que en la UNAM existe una cultura de género que propicia ambientes inhóspitos para las mujeres, cuya complejidad radica en su invisibilidad social.

Como problema de salud pública, el acoso sexual está asociado a agresiones sexuales que afectan la salud mental y reproductiva 3 , ya que existe el riesgo de experimentar abortos y de contraer infecciones de transmisión sexual 4. Por otro lado, varios estudios internacionales 5,6 han demostrado que se trata de un fenómeno poco denunciado, debido a las creencias que atribuyen a la mujer la responsabilidad de la agresión, lo que puede generar cuadros de depresión 7 relacionados con el estigma y la discriminación que viven las mujeres acosadas. Estos hallazgos coinciden con la investigación que Mingo 8 hizo en la UNAM, pues la autora asegura que el miedo a la muerte social que enfrentan las chicas que emprenden la denuncia penal contra el acosador es un factor decisivo para inhibir la denuncia.

Desde una perspectiva antropológica, y contextualizado en el ámbito de la vida escolar universitaria, entendemos el acoso sexual como una forma de violencia basada en el sistema sexo/género, porque se ejerce como una agresión que puede ser física y/o psicológica e implica relaciones de poder y control asimétricas entre el perpetrador y la víctima, quien generalmente ocupa una posición de subordinación 9 . Además, como lo señala Lamas 10, la orientación sexual de la víctima y la forma de asumir su género pueden ayudar a naturalizar el origen de esta violencia. Aunque consideramos que la violencia sexual está marcada por la desigualdad estructural del género, la etnicidad y la clase social, no necesariamente supone una relación vertical en sentido descendente por parte del acosador y el acosado, pues también puede ser horizontal o ascendente. Es decir, no obstante que el acoso sexual puede ser perpetrado en contra de cualquier persona, en este trabajo nos interesa analizar el que ejercen hombres contra mujeres, por eso partimos conceptualmente de que se trata de un dispositivo de género y patriarcal 11, que es inherente a la dominación masculina 12 , y entre sus efectos inmediatos se ha observado que afecta el derecho a la educación de las mujeres, pues se le asocia a la deserción escolar feminina 13,14 .

Otro aspecto conceptual que nos parece necesario destacar es que el acoso sexual universitario es parte de las formaciones sociales que sostienen la misoginia como forma de vida en varones 1, especialmente entre aquellos que construyen identidades consideradas como de hombres verdadeiros ${ }^{15}$. En un estudio realizado en la Universidad Autónoma de Chapingo (México) con jóvenes de origen rural, se detectó que esta violencia tiene su origen en la reproducción doméstica, pues la vida familiar 16 es una instancia de (re)producción de ideas sobre sometimiento, dependencia y recato femenino, creencias que fueron detectadas entre los jóvenes que participaron en el estudio y que son vistas como virtudes de las mujeres. Este planteamiento refuerza los hallazgos de investigaciones que relacionan el acoso sexual con las creencias sexuales estereotipadas 13 al atribuir a las víctimas actos "provocativos" que detonan la agresión.

Otros estudios sugieren que el acoso sexual puede ser ejercido para controlar la forma de vestir 17, tanto de estudiantes como de profesoras, lo que afecta notablemente la salud mental 18 de las personas afectadas. En algunos contextos este modelo de control tiene que ver con mujeres responsables del hostigamiento sexual 19 o bien estas asumen roles de encubrimiento 20 que favorecen la naturalización social de esta violencia. Además, no siempre ocurre en situaciones de tensión y coerción explícitas, es decir, puede operar desde la microfísica del poder propia del cortejo y de insinuaciones inherentes al machismo galante 21 , prácticas sociales que refuerza su invisibilización.

Si bien las mujeres han logrado reconocimientos históricos que sugieren cambios educativos importantes en México, en contextos de educación superior aún existen formas de hostigamiento 
que afectan el derecho a la educación. Un tema poco documentado es la resistencia cultural al acoso, de modo que en este artículo partimos del supuesto hipotético de que siempre hay expresiones de resistencia que pueden ser acciones y discursos que usan los actores vulnerados para afrontar las situaciones hostiles generadas por quienes detentan el poder. De ahí el interés por analizar las narrativas de estudiantes que experimentaron contextos de acoso, pero hacemos énfasis en la descripción de algunas de las prácticas de resistencia que muestran las estudiantes, en tanto intenciones de reivindicación del derecho a la educación libre de violencia.

\section{Método, trabajo de campo y universo de estudio}

El propósito del estudio fue conocer el acoso sexual y las dinámicas de resistencia que este suscita desde la perspectiva de las mujeres que estudian la carrera de derecho en una universidad pública de la Ciudad de México, de modo que recurrimos al enfoque fenomenológico de corte constructivista 22, un encuadre metodológico en donde lo real aparece como una trama de significados atribuidos por el sujeto a través del lenguaje. Este universo de sentido, por tanto, es susceptible de ser explorado a través de las narrativas orales. Así, nos basamos en entrevistas semiestructuradas que iniciaron como conversaciones informales y fueron grabadas con el consentimiento informado de las participantes, a quienes se les explicó el compromiso de mantener, como un derecho suyo, el anonimato y la confidencialidad de las entrevistas y de la información recabada. Esto forma parte del protocolo ético requerido por el comité de investigación social al que se apega el departamento de investigación al que pertenecemos los investigadores responsables.

El trabajo de campo duró poco más de dos semestres del calendario escolar universitario y se llevó acabo entre enero de 2016 y marzo de 2017. En total se entrevistaron a 14 personas: nueve son estudiantes mujeres, tres son estudiantes varones y dos son profesoras.

Además, se recurrió a la observación directa y al diario de campo. La observación de las clases nos permitió conocer los aspectos de la vida escolar relacionados con las materias y prácticas didácticas que las estudiantes consideran como expresiones o contextos de acoso. El acercamiento fue paulatino y estuvo definido por los tiempos y disposición de las informantes para conversar y, en algunos casos, pudimos además establecer contacto a través de Facebook, desde donde se dio continuidad a aquellas entrevistas que por alguna razón habían sido interrumpidas.

\section{Resultados}

\section{La pedagogía punitiva como dispositivo de acoso escolar}

La disciplina escolar es un dispositivo de control académico, y adquiere el carácter punitivo cuando se apoya en lo que Foucault 23 denomina la sanción normalizadora, un acto correctivo ligado a la idea de vigilancia y castigo, es decir, deviene en recurso para sancionar y encausar coercitivamente. En este sentido, la disciplina escolar es un dispositivo de poder y su rasgo distintivo en el ámbito analizado es que puede ejercerse a través de códigos de vestimenta basados en principios heteronormativos, por ejemplo, se detectaron prácticas disciplinarias muy eficientes de control social que determinan la reproducción de estereotipos de género:

"...hay un doctor que no te permite entrar a sus clases si no vas con traje, en el caso de los varones, y nosotras debemos ir con tacones, faldas y esas cosas, te dice que él trata solamente con abogados y hasta que vayas como tal, te permite ingresar a las clases" (Mujer, 22 años, estudiante de 6o semestre).

Aunque el reglamento oficial no estipula la obligación de uniforme o de vestimenta específica, la población estudiantil parece haber acatado como costumbre esta prohibición. Es de subrayar que no sólo implica un orden heteronormativo, en el caso de los varones conlleva además un sustrato ideológico de clase social que parece depositar en el traje y corbata el recurso de distinción y reconocimiento social, pues son símbolos de un estatus económico 24: 
E: "Muchos varones portan traje, ¿es parte del reglamento?”.

I: "No, pero hay maestros que piden que vengamos así, sobre todo a los hombres. Con nosotras no hay tanto problema, podemos venir con vestidito; aunque yo no entiendo por qué a ellos les piden que vengan vestidos así" (Mujer, 21 años, estudiante de 4 o semestre).

Los varones están obligados a asistir a clase con traje y corbata, y las mujeres con falda y tacón, este vestuario se convierte en el fetiche definitorio de identidad del estudiante de derecho, es un recurso simbólico con el que se figura la vida profesional de la abogacía. En esta diferenciación del vestir existe una vigilancia heteronormativa, cuyo fin es que la población estudiantil mantenga una vida apegada a los cánones de una masculinidad y feminidad ligadas al ideal de la profesión, sin embargo, se advierte un discurso sumamente coercitivo, cruzado por el género y la clase social.

Detectamos además un discurso moral que ayuda a comprender la idea de subordinación femenina como un dispositivo pedagógico de control social, por ejemplo, una estudiante describió el discurso de una profesora que les enseña que el éxito en la vida de las mujeres depende de que sean recatadas y sumisas ante las necesidades o deseos de los varones:

"Había una maestra que nos decía que debíamos hacer caso a los hombres, y que teníamos que comportarnos bien con ellos, si no, no conseguiríamos esposo” (Mujer, 22 años, estudiante de 6o semestre).

Además, las estudiantes deben asumir que nadie puede contravenir la opinión del profesor, especialmente si es en público. Las jóvenes aseguran que las formas más comunes de sanción que ejercen los profesores consisten en ridiculizar a las estudiantes frente al resto de sus compañeros, hostigarlas frente al grupo, cancelar su derecho a presentar examen o negarles el acceso a clases:

"En una de las opiniones que el profesor pidió en su evaluación como docente, habian dicho que era una persona literalmente grosera o poco amable; y mi opinión fue que a veces no era grosero, sino el tono en el que él se dirigía pudiese parecerlos. La respuesta del profesor fue 'ah, pues como usted opina eso, el primer examen que voy a calificar va a ser el suyo"' (Mujer, 21 años, estudiante de 6o semestre).

"En segundo semestre yo era como una chica muy despierta y me interesaba cuestionar todo, pero fue justo en segundo semestre cuando tomé clases con un profesor de derecho penal que me inhibió muchísimo. Me quitó el espíritu abierto que yo tenía, me lo inhibió absolutamente, porque él era una persona súper impositiva, que desde el primer día nos dijo que él tenía varios doctorados honoris causa. Además, se burlaba de los alumnos, siempre identificaba a tres, cuatro personas del salón y todo el semestre se la pasaba burlándose de ellos" (Mujer, 23 años, estudiante de 9o semestre).

Los dispositivos disciplinarios pueden tener efectos en las creencias y prácticas de la población estudiantil, así lo plantea una profesora, quien describe algunos cambios en los estudiantes mientras avanzan en la carrera:

"Cuando daba una clase de primer semestre y luego daba una clase de octavo, si era muy notoria la diferencia, los niños de octavo actúan como abogados, ya tienen una actitud más formal, ya no es tan fácil que uno critique las instituciones políticas y jurídicas de este país, ya te responden. Es decir, no es que los niños de primer semestre no te respondan, pero la mayoría le entran a la crítica y no tienen problema con eso; en cambio los chicos que ya están a punto de salir de la carrera ya asumen una actitud de abogado serio, formal, porque quizá eso es lo que le enseñamos los maestros, que asi es el abogado" (Mujer, 37 años, profesora).

Estas identidades de profesional, que parecen apegarse a un modelo conservador y autoritario, tienen un vínculo importante con el acoso, pues no sólo implica normas sociales de vestimenta, sino especialmente una visión del mundo que hace posible la aceptación de la vigilancia heteronormativa y algunas formas de hostigamiento sexual, por eso, creemos que favorecen la aceptación social del acoso como parte de la vida universitaria en esta escuela.

\section{Acoso escolar, impunidad y vida cotidiana}

En esta escuela hay un Plan de Desarrollo Institucional que busca fomentar el pensamiento crítico, el ejercicio ético de la profesión y el respeto a la diversidad en todas sus expresiones 25 . Se trata de un programa con intenciones bastante progresistas y que es de aplicación obligatoria por todos los estudiantes, los profesores y el personal administrativo. Sin embargo, en las aulas es común escuchar argumentos que favorecen la visión de un ejercicio profesional, apegado a intereses monetarios y de poder político, es decir, algunos profesores enseñan explícitamente a sus estudiantes que el Derecho es una disciplina al servicio de una elite privilegiada: 
“...mi objetivo no es que ustedes aprendan, sino que tengan poder y se traduzca en dinero; la justicia es del que tiene dinero, entonces, hagámosles justicia a los que pueden pagarnos" (Docente de tiempo completo, 20 años de antigüedad).

Estos mensajes promueven visiones sobre el uso del saber jurídico como dispositivo de poder económico y político. Forma parte de una pedagogía impartida en una escuela de leyes de la que se espera un modelo de enseñanza apegado a principios humanísticos sobre enseñanza de la justicia. En cambio, se muestra que la justicia es discrecional, porque está supeditada a un vínculo monetario y que, sin importar las faltas sociales cometidas, el acceso a la justicia es directamente proporcional al pago monetizado. Hablamos de un contenido pedagógico desesperanzador, en parte porque se trata de un discurso docente, pero también porque da cuenta de que el aula es un espacio de configuración ideológica que no siempre implica sustentos éticos:

"Cuando empecé la carrera de leyes no entendía muchas cosas y me sentía muy intimidada y muy poco respaldada por los demás compañeros; entonces, como que ese semestre no hice nada. De hecho, recuerdo que el profesor siempre ponía muchos ejemplos, para hablar de derecho penal, con las personas que ayudan en la casa, la ayuda doméstica, y siempre se refería a ellas como 'las chachas', o sea de una forma súper despectiva. También cuando empezó el semestre nos dijo: 'bueno, de esto se trata, el derecho penal reconoce que hay un árbol de manzanas, que la sociedad es como un árbol de manzanas, hay manzanas que nacen bien sanas y manzanas que nacen podridas, entonces el derecho penal se dedica a arrancar las manzanas podridas para que no contaminen a las manzanas sanas', era un tipo nefasto, nefasto. Ese semestre la pasé muy mal, iba sin ganas a la escuela" (Mujer, 21 años, estudiante de 9o semestre).

Un aspecto interesante de la vida escolar es que los pupitres están anclados al piso y alineados frente al escritorio del profesor, que se ubica en un podio elevado a unos cuarenta centímetros sobre el nivel del grupo. Esta arquitectura conlleva un lenguaje silencioso 26, cuyo fin es percibir a la figura docente como por encima del campo visual. Un uso del espacio que consigue enaltecer a los profesores como figuras máximas de autoridad y conocimiento. Además, en los muros hay placas con frases alusivas a un orden moral: "Eres el orgullo de tus padres, haz que crezca el orgullo", son adagios que parecen dictar conductas deseables en cada estudiante, pero que lleva implícito el mandamiento católico de "honrarás a tu padre y a tu madre".

En este contexto ideológico, el acoso existe habitualmente a través de agresiones de tipo sexual, físico y psicológicas provenientes de sus profesores. De hecho, señalaron al acoso sexual como la práctica de violencia más persistente: "no hay chava a la que no le pase". Esto da cuenta de la violencia sexual como un fenómeno que se ha normalizado por las propias víctimas y los espectadores. Por ejemplo, una forma bastante invisibilizada de acoso ocurre durante las clases, cuando algunos profesores expresan abiertamente su deseo sexual por las estudiantes:

"En una ocasión un profesor en la clase nos dijo 'y bueno, ya que aquí las mujeres, principalmente las de Derecho, se visten demasiado atractivas visualmente, $y$ la verdad es que hay unas que se ven bien buenas, $y$ se ven mejor cuando traen minifaldas”" (Mujer, 22 años, estudiante de 6o semestre).

"Había una compañera que siempre llevaba minifalda y cuando estábamos en clase, el profesor volteó directamente hacia la compañera y le dijo: 'le voy a pedir un favor, cuando decida traer pantalón, se sienta adelante; pero mientras le voy a pedir que se siente en algún otro punto donde no pueda ver sus piernas, porque me resultan distractores"'. (Mujer, 21 años, estudiante de 6o semestre).

El acoso se presenta de diversas formas, algunos docentes invitan abiertamente a sus alumnas a verse en contextos no académicos y con fines sexuales:

"Yo me llevo muy bien con un profesor, hace poco tiempo le comenté que estaba buscando trabajo y me dijo: 'no te preocupes, yo te ayudo', entonces intercambiamos teléfonos y le envíe mi currículum. Entonces un viernes en la noche él me manda un mensaje y me dice "oye, pues mira, tengo una conocida en tal lugar para que trabajes, pero dime, qué vas a hacer el fin de semana porque tengo que ir a Acapulco, vamos, acompáñame” (Mujer, 30 años, estudiante de 6 o semestre).

Otros recurren al correo electrónico para promover encuentros con estudiantes fuera de los ámbitos escolares, estas prácticas son más recurrentes con las estudiantes que son jefas de grupo, ya que los profesores aprovechan ese rol para obtener todos los datos de contacto (teléfonos, correos electrónicos, redes sociales). Sin embargo, de entre todos estos llama la atención un caso de acoso físico que se hace pasar como broma galante: 
"Ese profesor fue mi primera mala experiencia en cuestiones de acoso y hostigamiento porque lo que hacía es que, cuando salíamos de clase, él se ponía en la puerta y pedía que hiciéramos una fila para que todas las chicas, antes de entrar o salir de clase, le diéramos un beso en la mejilla. Pon tú que no era obligatorio y que, si no le dieras el beso, igual podías salir de clase, pero era súper molesto y muy agresivo para las que no queríamos hacerlo" (Mujer, 21 años, estudiante de 7o semestre).

Por otro lado, una profesora explicó que el acoso sexual no es una práctica que se ejerce exclusivamente contra las estudiantes, ella, como docente también lo padece. Sobre todo, enfatizó en el acoso sexual ejercido por los estudiantes contra las profesoras, solo que es un fenómeno que se invisibiliza. Si bien, no profundizaremos más en este hallazgo, es relevante para repensar la forma tan estereotipada de las víctimas y victimarios en el fenómeno de la violencia sexual, lo que abre la posibilidad de emprender nuevas investigaciones en las que se analicen diferentes tensiones en las relaciones de poder en la vida escolar. Es el caso de la segregación social, una forma de acoso poco documentada, y que es una de las formas que más ha dejado impronta en sus memorias, pues marca una distinción de privilegio que los profesores hacen para favorecer a los estudiantes varones:

"Hay profesores que para evaluar piden a los alumnos que se amarren la corbata y si saben amarrarse la corbata, ya pasaron el examen, pero las mujeres tenemos que hacer el examen para poder acreditar la calificación” (Mujer, 21 años, estudiante de 6o semestre).

Algunas estudiantes consideran que son agredidas en las clases a través de comentarios que las desvalorizan, pero que los profesores disfrazan de intenciones "didácticas" para que la comunidad estudiantil comprenda los problemas que atiende la jurisprudencia. Es el caso de un profesor que en clase enseñaba a sus estudiantes las contradicciones que ocurren en los procesos de divorcio:

“...hablando de divorcio, las mujeres reclaman que los maridos sean infieles, pero si estuvieran casadas con el hijo de Slim, quien sabe si reclamarían de la misma manera; cuando ven a alguien de ese nivel, van como perras tras ellos" (Varón, 58 años, docente).

En el discurso de este profesor hay una desvalorización pública de las mujeres, pero además observamos prácticas de clasificación y selección de mujeres, así notamos formas de violencia que se agudizan más con mujeres que usan ropa entallada. Destaca el caso de estudiantes que son representantes de grupo, estudiantes con bajo rendimiento escolar o cuando son de nuevo ingreso. Otro hallazgo tiene que ver con la culpa que aparece en los discursos de las estudiantes que fueron violentadas sexualmente. Hay quienes asumen haber propiciado esta violencia:

"Lo del trabajo fue de su propia iniciativa, porque yo no le dije: 'ayúdeme a conseguir trabajo'; yo le comenté que estaba buscando trabajo. A mi honestamente el profesor no me interesa, o sea, como en otro aspecto. La verdad si me sacó mucho de onda cuando me propuso ir a Acapulco, me dejó pensando; dije, o sea, no sé si yo di pie, es que cuando pasan esas cosas te quedas pensando: ¿yo di pie?; o sea, ¿yo le coqueteé?, ¿fui provocativa con él en mi forma de ser o de vestir? Solo traté de ser amable” (Mujer, 30 años, estudiante de 6o semestre).

Este relato expresa una negación del derecho que tienen las estudiantes a ser respetadas, se observa además una franca duda, atribuible a un remarcado sentimiento de culpa al creer que propició el acoso. Es justamente la idea del comportamiento provocativo lo que históricamente ha servido para justificar y naturalizar la violencia sexual contra las mujeres.

Un aspecto que llama nuestra atención es que el acoso se percibe por las alumnas como un delito que generalmente queda impune. Por eso, para algunas, la denuncia supone un riesgo innecesario, pues creen que pueden ser excluidas del acceso a los mercados de trabajo inherentes al ejercicio profesional de la carrera:

“....para qué denuncias?, ¿para qué te haces enemigos? Si en un futuro, en el mundo jurídico te los vas a encontrar y te pueden ayudar, te pueden (...), digamos te encuentras a estos compañeros en el mundo jurídico, en el desempeño de la profesión y ¿para qué te haces enemigos? Si te lo vas a encontrar, no sabes si al rato es secretario, es presidente, o no sé, que tenga algún puesto importante y te pueda ayudar" (Mujer, 21 años, estudiante de 6 o semestre).

El acoso no es denunciado, en parte porque no hay procesos de tipo penal en contra de los profesores, pues para las estudiantes la impartición de justicia parece poco fiable y, por eso, temen futuras represalias. Sin embargo, existen condiciones políticas que también favorecen que estas prácticas queden impunes, pues recientemente se reveló que los profesores que habían sido denunciados como acosadores ante tribunales universitarios no podrían ser removidos laboralmente, debido a su condi- 
ción de trabajadores sindicalizados 27 . Esto abre un panorama poco alentador en la lucha basada en la denuncia pública y judicial contra profesores acosadores.

\section{Las estrategias para sobrevivir al acoso}

Las estudiantes que han sido víctimas de agresiones sexuales prefieren no denunciar ni por la vía universitaria ni por la vía penal. Las razones son muy diversas, algunas refieren no hacerlo porque las denuncias al interior de la institución son tratadas discrecionalmente y, por lo tanto, algunos de los abusos quedan impunes con riesgo de que el acoso se agudice. Otras no denuncian por creer que serán vistas como causantes de su agresión, es decir, a las estudiantes no solo les preocupa que, al denunciar, las relaciones con sus profesores se vuelvan tensas, sino también la muerte social en el núcleo escolar inmediato. No obstante, especialmente les preocupa que al denunciar surjan asperezas con sus profesores o compañeros agresores, lo que podría tener consecuencias negativas en los espacios laborales. Particularmente, porque ante la escasez laboral que enfrentan las jóvenes, y ante los gremios de poder que suelen constituirse en las organizaciones, temen encontrarse con ellos en relaciones de subordinación en los espacios laborales, y ellos emprendan actos de venganza; o bien perder la oportunidad de ingresar al mercado laboral:

"Es muy difíil que se cuestione. Es que estos tipos siguen dando clase porque han vivido en una burbuja de impunidad. Eso es lo que pasaba con mi maestro que te conté, porque como él sabe siempre más de penal que tú, por más que tú le metas una denuncia penal y vayas al ministerio público, él siempre se va a poder defender mejor" (Mujer, 21 años, estudiante de 10o semestre).

Se suma el miedo a la impunidad y las redes de corrupción, pues no se atreven a denunciar formalmente por temor a desencadenar un proceso legal, en el que, al litigar, se vean en desventaja ante sus profesores en cuanto a conocimiento y experiencia en el litigio, pero sobre todo por las redes de corrupción que existen entre las autoridades que imparten justicia. En la siguiente narrativa, la joven da por hecho que, como estudiante, no tiene posibilidades de ganar un litigio con sus profesores porque asume que, si hay algún tipo de relación de amistad entre las autoridades judiciales y sus profesores, las posibilidades de ganar aún son menores:

"Hay un caso de una chica que denunció, no me sé bien el caso, pero hay una chica que denunció por hostigamiento a un profesor y el profesor le metió una denuncia por difamación; entonces es como el miedo de que ellos siempre saben más, o tienen contactos con jueces o con ministerios públicos o pueden llegar a arreglos. La verdad a mí si me da miedo meterme contra un penalista, porque siento que siempre más las puede aplicar más, sabes" (Mujer, 21 años, estudiante de 10o semestre).

Sin embargo, el que las estudiantes no denuncien por la vía institucional no las limita a hacerlo por vías que no son formales o a emprender acciones que operan bajo un discurso oculto, que las ayuda a afrontar las agresiones de quienes detentan el poder. Pueden ser acciones de carácter individual o colectivo, pero casi siempre no planeadas. Por ejemplo, hay estudiantes que optan por camuflarse para hacerles creer a sus profesores agresores, que son fieles subordinadas. Ante ellos niegan sus convicciones feministas, asumen códigos de vestimenta conservadores, e incluso, se masculinizan. No obstante, el camuflaje no siempre es suficiente, algunas han tenido que "pasar por perfil bajo" para mitigar estas agresiones:

"Bien, por perfil bajo me refiero a no intentar ser popular o no intentar mantener un perfil de la abogada estrella, mantener un perfil de alguien que pareciera que no estudia, que anda por ahí inmersa, a ser una estudiante más, que a ser una estudiante destacada. Prefiero no, tampoco prefiero relacionarme mucho con la gente de mi carrera. Prefiero mantenerme a distancia, es como ver el panorama, pero tú estás observando desde lejos; a eso me refiero con mantener perfil bajo, guardar ciertas opiniones, ciertas ideas para ti mismo" (Mujer, 21 años, estudiante de 60 semestre).

Otras estudiantes, en cambio, han optado por hacer públicas sus experiencias de acoso sexual y, en aras de mitigar este fenómeno, que según declaran ha hecho mucho mal a tantas mujeres, han conformado colectivos que pugnan contra estas prácticas escolares. Sus experiencias las han sacado del espacio privado para hacerlas colectivas, como dice Blanco 28 (p. 11) "la politización personal como el género y la sexualidad pasan a ser politizaciones colectivas". Lo hacen a través de actividades como el tendedero de las denuncias, que consiste en hacer de conocimiento público, en la explanada, los casos de acoso sexual o violencia con nombre y apellido de los agresores; colocan también buzones de denuncias en 
los pasillos y organizan foros de discusión jurídica con perspectiva de género, con la finalidad de sensibilizar a la comunidad universitaria. En la búsqueda de su objetivo, estos colectivos han sido objeto de persecución y censura por las autoridades universitarias y la comunidad estudiantil; no obstante, a pesar de las peripecias y los detractores en su contra, se mantienen muy activos.

El uso de las redes sociales es otra forma de denuncia y que transita de lo íntimo a lo público. En Facebook han encontrado el espacio para denunciar públicamente las experiencias que habían mantenido en privado. Y no solo denuncian, además utilizan este espacio como recurso de resistencia, ya que advierten a otras compañeras las formas de violencia que pueden enfrentar. Se comparten estrategias, prácticas y discursos que les ayudan a asumir la vida escolar sin el agravio del hostigamiento. Esto significa que las estudiantes han construido redes de acompañamiento que no necesariamente implican la presencia física pero que, desde lo virtual, dotan de herramientas que pueden contender exitosamente con esta forma de violencia escolar.

\section{Conclusiones}

La vida escolar es percibida por las mujeres como un contexto hostil del que se sienten rechazadas, lo que puede estar asociado a las prácticas heteronormativas o modelos disciplinarios que buscan definir conductas estudiantiles en apego a códigos de género y de clase social. Se trata de principios normativos, basados en un autoritarismo que pasa como parte de la vida académica, pero que da lugar a una suerte de currículum oculto que favorece la naturalización del acoso contra mujeres, pues existen formas de hostigamiento respecto a la forma de vestir y evaluar el rendimiento académico. Aunque es un modelo de hostigamiento que afecta a toda la población estudiantil, existen notables diferencias entre hombres y mujeres que están asociadas a la heteronormatividad que rige la disciplina escolar y en general los códigos de vestir e interactuar en las aulas.

El acoso no siempre es ejercido bajo situaciones de tensión y coerción explícitas, es decir, puede ocurrir de forma imperceptible, ligado a la microfísica del poder, ya que implica vínculos inherentes al cortejo galante, en donde los estereotipos de género refuerzan su normalización. Por ejemplo, se observaron prácticas que operan entre lo público y lo privado, pues al tiempo que pueden ser acosos sutiles y discretos, como llamadas telefónicas o escritos enviados a través de correo electrónico, también hay agresiones francas y evidentes que incluyen invitaciones para viajar o para formar parte de equipos de trabajo a cambio de encuentros sexuales. Esta dinámica la ligamos a la representación social y cultural que atribuye a las estudiantes la responsabilidad de la agresión, lo que favorece el silencio, la depresión y la escasa denuncia. Es decir, las estudiantes tienden a normalizar su propio acoso, al punto en que resignación y culpa juegan un rol pasivo, pero definitivo, en el proceso de habituación de la violencia como parte de la vida cotidiana escolar analizada.

No obstante, se advierten los primeros esfuerzos institucionales para contender con el acoso sexual de las mujeres, entre las autoridades escolares no parece haber un posicionamiento legítimo ni ético para enfrentar este problema. El estudio sugiere que es a través de acciones organizadas por las estudiantes como se ha conseguido denunciar y resistir. En ese sentido, entre los logros más interesantes está el reconocimiento del silencio y la impunidad como formas de sometimiento que parecen ser atendidas por algunas estudiantes desde una lógica ciudadana que persigue el derecho a la educación libre de violencia. Lo que parece indicar que, aún en los espacios más hostiles, hay lugar para desnaturalizar el acoso, pues encontramos que algunas estudiantes recurren a organizaciones estudiantiles para exhibir a los profesores que son reconocidos generacionalmente como acosadores. Se trata de un modelo de respuesta organizada que invita a repensar a la escuela como un contexto en el que la organización estudiantil contra esta forma de violencia es en sí un proceso formativo poco documentado. Esto resulta especialmente importante si se considera el contexto, es decir, aunque la violencia analizada empieza a ser nombrada y desnaturalizada, ocurre en una de las universidades públicas más importantes del país, pero además en un ámbito de formación educativa, que tiene el propósito de enseñar modelos de impartición de justicia, una institución que tendría que ser referencia en la eliminación del acoso escolar. 


\section{Colaboradores}

D. Hernández-Rosete participó de la elaboración del marco teórico y desarrollo de método general de la investigación, redacción de problematización y definición del objeto de estudio etnográfico, diseño de instrumentos y coordinación general del trabajo de campo, redacción y análisis de hallazgos y elaboración de conclusiones. J. C. Gómez-Palacios colaboró en la elaboración de trabajo de campo, entrevistas en profundidad, transcripción y análisis de entrevistas y en la escritura del borrador.

\section{Informaciones adicionales}

ORCID: Daniel Hernández-Rosete (0000-00034030-2663); Juan Carlos Gómez-Palacios (00000002-9246-523X).

\section{Referencias}

1. Martínez C. Las instituciones de educación superior y el mandato de masculinidad. Nómadas 1919; 51:117-33.

2. Corleto AB, Mingo A, Moreno H, Cooper J. Intrusas en la Universidad. Ciudad de México: Universidad Nacional Autónoma de México; 2013.

3. Romito P, Cedolin C, Bastiani F, Beltramini L, Saurel-Cubizolles MJ. Sexual harassment and menstrual disorders among Italian university women: a cross-sectional observational study. Scand J Public Health 2017; 45:528-53.

4. World Health Organization. Global and regional estimates of violence against women: prevalence and health effects of intimate partner violence and non-partner sexual violence. Geneva: World Health Organization; 2013.

5. Adinew YM, Hagos MA. Sexual violence against female university students in Ethiopia. BMC Int Health Hum Rights 2017; 17:19.

6. Dartnall E, Jewkes R. Sexual violence against women: the scope of the problem. Best Pract Res Clin Obstet Gynaecol 2013; 27:3-13.

7. Boyle KM, McKinzie AE. The prevalence and psychological cost of interpersonal violence in graduate and law school. J Interpers Violence 2018; [Online ahead of print].

8. Mingo A. El ocioso intento de tapar el sol con un dedo: violencia de género en la universidad. Perfiles Educativos 2015; XXXVII:138-55.

9. Quick J, McFadyen M, Sexual harassment: have we made any progress? J Occup Health Psychol 2017; 22:286-98.

\section{Agradecimientos}

Agradecemos a las mujeres que compartieron sus narraciones y que ayudaron a comprender la esperanza latente en un movimiento social. Agradecemos al Consejo Nacional de Ciencia y Tecnología por el financiamiento.

10. Lamas M. Acoso. ¿Denuncia legítima o victimización? Ciudad de México: Fondo de Cultura Económica; 2018.

11. Segato R. Las estructuras elementales de la violencia: ensayos sobre género entre la antropología, el psicoanálisis y los derechos humanos. Buenos Aires: Prometeo; 2010.

12. Bourdieu P. La dominación masculina. Barcelona: Anagrama; 2000.

13. Hernández C, Jiménez M, Guadarrama E. La percepción del hostigamiento y acoso sexual en mujeres estudiantes en dos instituciones de educación superior. Revista de la Educación Superior 2015; XLIV:63-82.

14. Ortiz-Hernández L, Compeán-Dardón MS, Gallardo-Hernández G, Támez-González S, Pérez-Salgado D, Verde-Flota E. Harassment experiences among students of health-related professional careers in Mexico. Gac Med Mex 2010; 146:25-30.

15. Connell R, Messerschmidt J. Hegemonic masculinity: rethinking the concept. Gend Soc 2005; 19:829-59.

16. Castro R, Vázquez V. La universidad como espacio de reproducción de la violencia de género. Un estudio de caso de la Universidad Autónoma de Chapingo. Estudios Sociológicos 2008; XXVI: 587-616.

17. Wood L, Hoefer S, Kammer-Kerwick M, ParraCardona JR, Busch-Armendariz N. Sexual harassment at institutions of higher education: prevalence, risk and extent. J Interpers Violence 2018; [Online ahead of print]. 
18. Sivertsen B, Nielsen MB, Madsen IEH, Knapstad M, Lønning KJ, Hysing M, Sexual harassment and assault among university students in Norway: a cross-sectional prevalence study. BMJ Open 2019; 9:e026993.

19. Barreto M. Violencia de género y denuncia pública en la universidad. Revista Mexicana de Sociología 2017; 79:261-8.

20. López L. Manifestaciones del acoso escolar ¿los chicos acosan de forma diferente que las chicas? Revista Iberoamericana de Educación 2013; 62:1-13.

21. Inciarte E. El machismo galante. Ciudad de México: Plaza y Valdés; 1994.

22. Berger P, Luckmann T. La construcción social de la realidade. Buenos Aires: Amorrortu; 2015.

23. Foucault M. Vigilar y castigar: nacimiento de la prisión. Ciudad de México: Siglo XXI; 2009.
24. Moreyra C. Entre lo íntimo y lo público: la vestimenta en la ciudad de Córdoba a fines de Siglo XVIII. Fronteras de la Historia 2010; $15: 388-90$

25. Contreras R. Plan de desarrollo institucional 2016-2020. Ciudad de México: Facultad de Derecho, Universidad Nacional Autónoma de México; 2016.

26. Hall E. La dimensión oculta. Ciudad de México: Siglo XXI; 2003.

27. Moreno T. UNAM, sin castigar a maestros acosadores. Diario El Universal 2019; 6 dic. https://www.eluniversal.com.mx/nacion/enla-unam-sindicatos-protegen-acosadores.

28. Blanco R. Escenas militantes: lenguajes, identidades políticas y nuevas agendas del activismo estudiantil universitário. Buenos Aires: Consejo Latinoamericano de Ciencias Sociales; 2017. 


\section{Abstract}

This article describes harassment practices in higher education and explains why they are taken for granted, besides documenting forms of resistance reported by some students and professors. From January 2016 to March 2017, nine in-depth interviews were held with students who had experienced harassment at a public school of law in Mexico City, Mexico, besides interviews with three male students and two female professors. The findings suggest that some professors harass selectively, based on dress codes associated with gender stereotypes. Harassment can be viewed as an exemplary punishment with corrective purposes, or part of school discipline and the formation of female students' identity at the institution. The study also detected forms of heteronormative vigilance that take harassment for granted, to the degree that some female students consider it part of a lifestyle to which they have to adapt in order to complete their studies. Other female students have found ways of denouncing harassment, through informal strategies by which they have contributed to exposing and denaturalizing this gender violence. For example, some professors have ordered female students to wear skirts when taking exams, but this order is not always obeyed, and the students that have refused have organized resistance movements. Thus far there has been no intervention by the university administration to guarantee harassment-free spaces for women, which highlights the need to create guidelines and rules for higher education that allow typifying such acts as serious offenses and preventing sexual harassment.

Bullying; Higher Education; Violence

\section{Resumo}

Este artigo descreve algumas práticas de assédio no ensino superior e explica por que estão se naturalizando. Também se documentaram as formas de resistência narradas por algumas estudantes universitárias e professoras. Entre janeiro de 2016 e março de 2017 foram realizadas nove entrevistas em profundidade com estudantes universitárias que vivenciaram situações de assédio na faculdade pública de direito na Cidade do México, México, além de três estudantes homens e duas professoras. Delas se desprende que determinados professores assediam seletivamente, com base em códigos vestimentários relacionados com os estereótipos de gênero. $O$ assédio pode ser visto como um castigo exemplar, tendo um propósito corretivo, isto é, seria parte da disciplina escolar e da formação identitária das universitárias daquela instituição. Também foram detectadas formas de vigilância heteronormativa que naturalizam o assédio a ponto de algumas considerá-lo parte de um modo de vida ao que precisam se adequar para conseguir concluir os estudos. Outras encontraram formas de denunciar, por meio de estratégias informais, pelas quais contribuíram para dar visibilidade e desnaturalizar esta violência de gênero. Por exemplo, apesar de alguns docentes determinarem o uso de saia como requisito para fazer as provas, nem todas as universitárias acatam tal exigência e as que recusam organizaram movimentos de resistência estudantil. Até agora, não houve qualquer ação por parte das autoridades, no sentido de garantir às mulheres espaços livres de assédio, o que realça ainda mais a necessidade de criar estatutos e regulamentos no ensino superior que tipifiquem tais delitos como graves, de modo a coibir o assédio sexual.

Bullying; Educação Superior; Violência
Recibido el 04/Mar/2020

Versión final presentada el 18/May/2020

Aprobado el 19/Jun/2020 